\title{
Precocious Puberty, CTCAE 5.0
}

National Cancer Institute

\section{Source}

National Cancer Institute. Precocious Puberty, CT CAE 5.0. NCI Thesaurus. Code C146645.

A disorder characterized by unusually early development of secondary sexual features; the onset of sexual maturation begins usually before age 8 for girls and before age 9 for boys. 